\title{
FACTORES DE IMPULSO EN LA CONFIGURACIÓN DE UN TERRITORIO INNOVADOR: \\ LA CONTRIBUCIÓN DEL ENTORNO AL SISTEMA PRODUCTIVO DEL CALZADO ALICANTINO*
}

\author{
Gabino Ponce Herrero \\ Antonio Martínez Puche \\ Dpto. Geografía Humana \\ Universidad de Alicante
}

\section{RESUMEN}

La innovación social va por delante de la innovación empresarial. Son las instituciones las que desarrollan las líneas de actuación más innovadoras. En general han sido gobiernos locales comprometidos los que han propiciado el mantenimiento y desarrollo ajustado del subsector. Las estrategias sectoriales se han sustentado en directrices globales, encaminadas a la ordenación y equipamiento del territorio, a la mejora del bienestar social y a la creación de empleo, apoyados en planes estratégicos y guiados por agencias de desarrollo local bien gestionadas.

Palabras clave: Innovación social, sistemas productivos locales, redes de cooperación, proyectos asociados.

\begin{abstract}
Motivating factors in the shaping of an innovative region: environmental contributions to the production system of the footwear industry in Alicante. Social innovation precedes commercial innovation. The most forward-looking plans of action are those developed by public institutions. In general terms, it is thanks to committed, local governments that favourable conditions for the footwear industry's maintenance and competitive development have been created. Strategies for this sector are based on global guidelines for the regulation and infrastructure of the region, improving social welfare and creating jobs. These sectorial proposals are backed by strategic plans and carried out under the supervision of well-run local development agencies.
\end{abstract}

Key words: social innovation, local productive system, networks, partnesship.

* Proyecto coordinado BSO2000-1422-CO9-02. 


\section{Una renovada vitalidad en la industria zapatera}

Una vez corregidos en buena parte los factores externos al subsector del calzado, y acomodada la economía española a nuevos parámetros -integración europea, moneda única, control de la inflación, marco global de competencia, etc. - desde mediados de la década de los años 1990 se asiste a un proceso de revitalización de los indicadores del calzado, que resultan impensables para un subsector tan amenazado como señalaban los análisis elaborados tras la fuerte crisis experimentada desde la segunda mitad de los años 1970. Recuperada la capacidad de empleo, en 1997 el calzado ocupaba el primer lugar en la Comunidad Valenciana, de un total de 35 ramos de actividad industrial, según la cantidad total de trabajadores del sector, con 35.457 empleados —a los que se debe sumar el trabajo informal-, el segundo lugar según los ingresos de explotación, con 578.690 millones de pesetas, sólo detrás de la industria del automóvil y sus componentes, pero el primer lugar conforme al incremento anual de los gastos de explotación (variación del 47'5\% entre 1996 y 1997), en noveno lugar de acuerdo con la inversión en activos materiales, con una productividad media, en términos de ingresos de explotación por empleado que la sitúa en mitad de la tabla — junto con el juguete-, por debajo de otros subsectores más mecanizados y muy por encima de otros también manufactureros como la madera y mueble, el textil y la confección.

Tales signos vitales quedan claramente reflejados en las cifras de exportación, que se han elevado desde los 95 millones de pares de 1992 hasta los 153 millones de 1997 - o los 144 millones de 1999 - o en el mismo incremento de las unidades productivas, que ascendieron desde las 2.453 censadas en 1995 hasta las 3.133 registradas en 1997. Sin embargo, a la vez que se observan nuevos procesos en las empresas, ligados a innovaciones en la organización, en la producción y en la comercialización, en el sector perviven muchos de los aspectos considerados negativos, que en gran medida constituyen el sustrato en que se apoyan los procesos de reestructuración acometidos.

Los aspectos que han renovado la vitalidad del calzado pueden agruparse en tres grandes conceptos: la incorporación de nuevas técnicas de organización, producción y comercialización (innovación tecnológica), ajuste en las magnitudes de las empresas y del propio subsector a las cambiantes demandas de un mercado globalizado y en competencia constante y, de manera especialmente significativa, apoyo en las instituciones y agentes sociales — públicos y privados—. Esto es, en el cambio hacia nuevas dinámicas competi-

EVOLUCIÓN DE LA PRODUCCIÓN POR TIPO DE CALZADO (MILES DE PARES)

\begin{tabular}{|l|r|r|r|r|r|}
\hline piel & $\mathbf{1 9 9 7}$ & $\mathbf{1 9 9 8}$ & $\mathbf{1 9 9 9}$ & $\mathbf{2 0 0 0}$ & $\mathbf{2 0 0 1}$ \\
\hline señora & 89.386 & 89.867 & 84.872 & 84.165 & 78.682 \\
caballero & 52.196 & 49.922 & 40.452 & 38.814 & 37.048 \\
niño & 29.325 & 31.659 & 25.084 & 22.820 & 23.053 \\
subtotal & 170.907 & 171.448 & 150.408 & 145.799 & 138.783 \\
caucho/plástico & 5.147 & 5.888 & 11.216 & 9.723 & 10.832 \\
textil & 27.588 & 39.913 & 41.775 & 38.364 & 50.517 \\
zapatillas y otros & 3.896 & 3.630 & 9.504 & 8.797 & 9.250 \\
subtotal & 36.631 & 49.431 & 62.495 & 56.884 & 70.599 \\
total & 207.538 & 220.879 & 212.903 & 202.683 & 209.382 \\
\hline
\end{tabular}

Fuente: Federación de Industrias del Calzado Español (FICE). Elaboración propia. 
PRODUCCIÓN DE CALZADO POR ZONAS GEOGRÁFICAS, 2001

\begin{tabular}{|l|r|r|r|r|}
\hline & miles de pares & $\%$ & millones $€$ & $\%$ \\
\hline Comunidad Valenciana & 129.498 & 61,8 & $2.062,5$ & 65,3 \\
Castilla-La Mancha & 19.919 & 9,5 & 336,6 & 10,7 \\
La Rioja & 15.680 & 7,5 & 208,1 & 6,6 \\
Aragón & 11.592 & 5,5 & 156,6 & 5 \\
Murcia & 9.829 & 4,7 & 99,1 & 3,1 \\
Andalucía & 1.561 & 0,7 & 20,2 & 0,6 \\
otras & 16.496 & 7,9 & 108,8 & 3,4 \\
total & 209.382 & 100 & $3.157,6$ & 100 \\
\hline
\end{tabular}

Fuente: FICE. Elaboración propia.

tivas ha resultado fundamental el aprovechamiento más intensivo del entorno por parte de las empresas; de un territorio que se ha dotado de nuevas infraestructuras y equipos, y que ha mejorado los niveles de bienestar y asistenciales, hasta configurar un territorio innovador, que genera activos propios aprovechados por la industria del calzado.

\section{La configuración territorial del sistema productivo industrial del Valle del Vinalopó}

Las comarcas del Alto, Medio y Bajo Vinalopó son las principales responsables del destacado valor añadido bruto que alcanza el subsector del calzado en el valor de la producción de la provincia de Alicante, de la Comunidad Valenciana y del conjunto del Estado. En los últimos cinco años, al socaire de una serie de coyunturas favorables, el crecimiento relativo del número de industrias ha sido elevado. En 1997 se censaron 2.238 empresas dedicadas a la fabricación de calzado en serie, así como a la fabricación de partes y accesorios de cuero para el calzado. La concentración más importante se da en Elche, con 916 empresas, seguida de Elda, con 487, Villena con 201, Petrer con 200 y Crevillente con 163. En conjunto, en el sistema productivo del calzado alicantino se elabora más del $60 \%$ de la producción estatal de calzado y se genera el 50\% del empleo del subsector en España. Todavía es posible identificar un apéndice territorial, constituido por la comarca del Corredor de Almansa, que prolonga la producción zapatera más allá del umbral provincial, y presenta una característica especialización en calzado de caballero ${ }^{1}$.

En el Bajo Vinalopó, Elche capitaliza un sistema productivo que se extiende por el territorio «rural» de la comarca vecina del Bajo Segura, subordinado funcionalmente. En ese entorno se produce el $62 \%$ del total provincial y el $41 \%$ de la producción estatal. El Valle Medio del Vinalopó — capitalizado por Elda - aporta el 30\% a la producción provincial y el $20 \%$ a la producción nacional de calzado, mientras que el Alto Vinalopó representa el $8 \%$ y el $5 \%$ respectivamente de la producción zapatera provincial y estatal.

Rasgo significativo ha sido el de la especialización territorial en diferentes tipos de calzado, que halla explicación precisamente en el trabajo en red en cada uno de los sistemas productivos locales — cada municipio—, aprovechando al máximo el principal recurso, el conocimiento especializado de la mano de obra, y las dinámicas de proximidad. De ese modo, mientras Elche presenta una producción de calzado diversificada (aunque la imagen de marca es el calzado deportivo), en Elda, Petrer y Sax más del $94 \%$ de la

1 PONCE HERRERO, G., «La industrialización de un área periférica: el Corredor de Almansa», Estudios Geográficos, Madrid, no 192, 1988, pp. 399-420. 
producción se destina a calzado de señora, de calidad media-alta, y en Villena más del 90\% de la producción se centra en el calzado de niño, de calidad media-alta, y en calzado especial ortopédico.

\section{De recursos genéricos a activos territoriales específicos}

Algunos estudios sobre el origen de la industria del calzado en el Valle del Vinalopó se han alineado con la tradición schumpeteriana, que considera la innovación como resultado del esfuerzo individual, desarrollado por empresarios u organizaciones, en un territorio estático e indiferente. No obstante, son más los análisis que, como éste, abordan el estudio a partir de un enfoque estructuralistas, entendido como tal el estudio de las múltiples y variadas relaciones establecidas entre la actividad humana y un territorio, resultado de sucesivas estrategias colectivas, cuyas características no son indiferentes sino que actúan como factores de impulso o freno a los procesos, dentro de un contexto socioeconómico determinado, que ha impuesto limitaciones, pero que, a la vez, ha permitido un notable margen de discrecionalidad en las actitudes y decisiones de los diferentes agentes locales ${ }^{2}$.

El calzado es una actividad industrial de localización libre. Se entiende por tal aquella actividad poco sensible a los costes de transporte, tanto de materias primas como de productos acabados, y que, por tanto, puede ubicarse en cualquier lugar: las materias primas proceden de otros lugares y los mercados se establecen en otros países. No obstante, tal afirmación debe ser matizada por cuanto el subsector se ha visto afectado en su devenir por el coste de la mano de obra, dada su elevada participación en el coste final del producto. De ese modo, parece aspecto significativo la presencia de una artesanía previa en el lugar donde surge - recurso cultural- A la vez, en los últimos tiempos, el subsector se ha mostrado especialmente atraído en su localización por la presencia de economías de aglomeración — recurso ambiental- (infraestructuras y equipamiento de carácter general que son aprovechados).

INVERSIONES EN EL SISTEMA PRODUCTIVO DEL CALZADO, AÑO 2000

\begin{tabular}{|l|r|r|r|r|r|r|r|}
\hline & $\begin{array}{c}\text { Maquinaria, } \\
\text { instalaciones } \\
\text { y utillaje }\end{array}$ & $\begin{array}{c}\text { Otras } \\
\text { inversiones } \\
\text { de equipo }\end{array}$ & $\begin{array}{c}\text { Terrenos, edificios } \\
\text { y otras } \\
\text { construcciones }\end{array}$ & $\begin{array}{c}\text { Total } \\
\text { inversiones }\end{array}$ & $\begin{array}{c}\text { Potencia } \\
\text { instalada } \\
(\mathbf{k W})\end{array}$ & $\begin{array}{c}\text { Número } \\
\text { de } \\
\text { establecimientos }\end{array}$ & $\begin{array}{c}\text { Puestos } \\
\text { de trabajo } \\
\text { creados }\end{array}$ \\
\hline Alto Vinalopó & & & & & & & \\
Total Inversión & 711.975 & 79.930 & 271.589 & 1.063 .494 & 3.619 & 38 & 206 \\
Cuero & 10.605 & 12.190 & 28.395 & 51.190 & 33 & 1 & 12 \\
Calzado & 74.350 & 45.740 & 51.400 & 171.490 & 438 & 10 & 80 \\
total subsector & 84.955 & 57.930 & 79.795 & 222.680 & 471 & 11 & 92 \\
Medio Vinalopó & & & & & & & \\
Total Inversión & 839.811 & 296.652 & 384.361 & 1.520 .824 & 9.700 & 80 & 548 \\
Cuero & 2.145 & 9.950 & 6.630 & 18.725 & 33 & 2 & 14 \\
Calzado & 213.837 & 242.064 & 16.000 & 471.901 & 1.701 & 30 & 349 \\
total subsector & 215.982 & 252.014 & 22.630 & 490.626 & 1.734 & 32 & 363 \\
Bajo Vinalopó & & & & & & & \\
Total Inversión & 845.086 & 1.120 .034 & 446.325 & 2.411 .445 & 8.454 & 95 & 924 \\
Cuero & 0 & 0 & 0 & 0 & 0 & 0 & 0 \\
Calzado & 363.741 & 693.208 & 194.200 & 1.251 .149 & 4.740 & 50 & 677 \\
total subsector & 363.741 & 693.208 & 194.200 & 1.251 .149 & 4.740 & 50 & 677 \\
\hline
\end{tabular}

Fuente: Conselleria d'Indústria i Comerç, 2001. Elaboración propia.

2 MÉNDEZ GUTIÉRREZ DEL VALLE, R., Geografía económica, Barcelona, Ariel, 1997, 384 pp. 


\subsection{Capitales exiguos y mercado de trabajo flexible y cualificado}

Del análisis realizado se observa el mantenimiento de buena parte de las constantes identificadas en la crisis: altos costes laborales contrarrestados mediante el recurso a la economía informal (hasta el $40 \%$ en estimación de los sindicatos en pleno año 2000), atomización de las unidades de producción (en 1997 las empresas de producción de calzado registraban una media de 11 empleados por unidad), inversión limitada (el esfuerzo inversor, definido como el cociente entre la inversión en activos materiales y los consumos corrientes, sirve para comparar la intensidad de la inversión realizada; según ese indicador, el subsector del calzado ocupa el penúltimo puesto de los 35 ramos clasificatorios de la Consellería de Industria ${ }^{3}$ ).

Como en épocas pasadas, en la actualidad la inversión procede de la autocapitalización, en multitud de fases acumulativas, que permiten dar el salto cualitativo desde el taller hasta la verdadera fábrica. Los procedimientos más usuales siguen siendo los mismos que en el siglo pasado. El emprendedor alquila la nave y la maquinaria, o compra la maquinaria mediante préstamos y alquila la nave. También es frecuente que el emprendedor posea la nave y, a veces, la maquinaria, procedentes de quiebras anteriores. En todos los casos, se parte desde una notable carencia de capital, reflejada en la frecuencia de empleo de maquinaria y naves de «segunda mano» y en alquiler, consignados como partida destacada en los gastos de explotación ${ }^{4}$. El calzado y la marroquinería constituyen subsectores muy sujetos a las oscilaciones de la demanda y, por ello, con un elevado grado de incertidumbre y riesgo. El capital circulante es elevado y los riesgos de impagados también. Todo ello contribuye a la perpetuación de una acusada falta de capitalización y a un endeudamiento crónico. Paradójicamente, buena parte de los beneficios, lejos de reinvertirse en la empresa, se desvían hacia valores más seguros.

Esa gran dependencia de la demanda — subsectores de demanda débil— es la que ha llevado a los empresarios a solicitar de manera insistente la flexibilización del mercado laboral y, en algunos casos, como en los subsectores del calzado y la marroquinería, a pedir la consideración de trabajo estacional, en atención a la fuerte vinculación de la producción con el ritmo de las campañas de moda. La reivindicación empresarial pretende regularizar el mercado laboral y las variadas relaciones contractuales existentes mediante los contratos de tipo fijo discontinuo (recientemente aprobado) como fórmula beneficiosa para empresarios — que pueden ajustar las plantillas a las temporadas de trabajo- y para trabajadores — que ven regulados de forma legal sus contratos-.

Esos nuevos modelos de contratación, junto a la bonanza económica han contribuido a hacer aflorar buena parte del empleo informal existente. No obstante, en el estado actual del ajuste del sistema productivo del calzado, la ocultación de una parte de la producción está resultando fundamental para mantener los niveles de competitividad que exige la internacionalización de los mercados y, con ella, el empleo — formal o informal—. Otra cosa es el enquistamiento del empleo informal detectado en bastantes casos, que parece evidenciar que ese tipo de empleo no se trata de un recurso coyuntural sino, más bien, forma parte consustancial de la estructura, lastrando los cambios hacia modelos productivos en que la competitividad venga dada por la innovación. Entre tanto, el entorno contribuye a mitigar los costes sociales derivados de los bajos salarios, de la precariedad del empleo y de la inestabilidad del mercado de trabajo.

3 IVE, Estadística Industrial. Comunitat Valenciana, Valencia, Instituto Valenciano de Estadística, 2000, 264 pp.

4 En el Valle del Vinalopó es común la presencia de acaparadores de naves y maquinaria industrial, adquiridas en subastas tras las frecuentes quiebras, que ofrecen sus servicios a los emprendedores. 
En síntesis, los recursos genéricos del territorio, encabezados por el conocimiento - saber hacer-, la iniciativa, las condiciones de bienestar social, el equipamiento y las infraestructuras — de tipo industrial y social—, junto con el compromiso de los gobiernos locales para el mantenimiento, diversificación y fomento de la actividad industrial, constituyen recursos genéricos — presentes en muchas partes- que adquieren la consideración de activos territoriales específicos, directamente implicados en el proceso evolutivo de la industria del calzado.

\subsection{Las condiciones geográficas: ventajas comparativas}

Resulta evidente la importancia que reviste la ubicación de un territorio dentro de un ámbito mayor de desarrollo potencial caracterizado por una red fluida de comunicaciones. En este sentido, las dinámicas territoriales dependen en gran medida de la capacidad de generar nuevos procesos interactivos. Puede decirse por ello que la génesis de un territorio industrializado en el nexo de comunicaciones del Valle del Vinalopó alcanza justificación, precisamente, por el papel histórico desempeñado por esas infraestructuras. Podría insistirse en esta justificación para explicar el desigual desarrollo experimentado por las ciudades literalmente cruzadas por el camino y el ferrocarril, por un lado, y los otros municipios que ocupan posiciones más marginales en el corredor, con un desarrollo retardado y menor.

El Camino de Madrid hacia el puerto de Alicante ha sido ventaja comparativa, convertida en ventaja competitiva con la instalación del ferrocarril, las modernas autovías y las diferentes estaciones de carga y descarga (aeropuerto y puerto). Hoy día, ese flujo se complementa con las nuevas dinámicas interterritoriales, que han potenciado el eje de desarrollo de la fachada mediterránea, con sentido norte-sur, y conecta las regiones de Valencia y Murcia con la dorsal centroeuropea de fuerte desarrollo ${ }^{5}$. En tal megaestructura, el Valle del Vinalopó sigue ocupando una situación privilegiada y es pieza destacada en su articulación territorial ${ }^{6}$.

\subsection{Los recursos no convencionales}

La fuerte crisis económica padecida en la segunda mitad de los años 1970 tuvo sus causas en cuestiones locales y globales (alzas saláriales, nuevas medidas fiscales, tipos de cambio, invasión de productos exteriores más baratos, entre otras). Los problemas de fondo fueron de tres tipos: factores financieros, debidos a la reducida tasa de inversión y a los altos tipos de interés vigentes; factores estructurales, dado que el subsector seguía el modelo productivo de los años 1960 (fuerte componente de mano de obra, baja productividad, pequeño tamaño de las empresas y falta de cultura empresarial), y factores externos, vinculados, por un lado, con la necesidad de importar la mayor parte de unas encarecidas materias primas y, por otro lado, por el desvío de la inversión extranjera hacia otros yacimientos de mano de obra.

El cúmulo de adversidades fue superándose en los años 1980 merced a la aparición de dos dinámicas, desarrolladas en paralelo: la desviación de parte de la producción hacia el trabajo clandestino, que ha reducido los costes de producción y se halla en la base de la supervivencia de multitud de empresas que «sumergen» todas o algunas fases del proceso

5 PEDREÑO MUÑOZ, A., «Un eje de expansión económica: Cataluña-Mediterráneo», España económica, Madrid, Espasa-Calpe, 1989, pp. 797-827.

6 PONCE HERRERO, G., «Industria y medios de transporte en los corredores de Almansa y del Vinalopó», Investigaciones Geográficas, nº 18, I.U.G., Universidad de Alicante, 1997, p. 100. 
productivo y, por otro lado, los esfuerzos desarrollados para ofrecer un calzado de más calidad, en busca de acceder a los segmentos más cualificados y exigentes de la demanda, a precios sensiblemente más elevados que el calzado ordinario, pero considerablemente competitivos en relación con los de otros países productores de calzado de calidad.

La coexistencia de ambos procesos permite hablar, a la vez, de estrategias reactivas y de estrategias proactivas, de la convivencia de empresas que buscan competir explotando con mayor intensidad el recurso genérico de la mano de obra, con empresas que desarrollan proyectos de I+D propios, o que se apoyan en la red de centros de transferencia tecnológica para la puesta en marcha de estrategias de innovación. En absoluto muestran trayectorias aisladas, sino que ambos tipos de empresas, tradicionales e innovadoras, confluyen frecuentemente en proyectos y campañas de tipo joint venture y, por lo general, en relaciones jerárquicas de subcontratación. Una y otra actitud se sustentan en el aprovechamiento de la cultura industrial del territorio: cultura organizativa, capacidad de gestión, cualificación y formación de los recursos humanos (mano de obra y empresarios), capacidad de cooperación y existencia de una densa red de relaciones sociales.

Puede concluirse que, globalizada la producción de calzado, el saber hacer y la iniciativa son los principales activos del sistema productivo local del Vinalopó. El Valle puede caracterizarse, a todos los efectos, como un territorio que aprende, un contexto donde se explota la economía del conocimiento y se saca el máximo partido a las dinámicas de proximidad. No obstante, dado el desequilibrio entre estrategias reactivas y proactivas, difícilmente puede ser considerado un territorio inteligente.

\subsubsection{Las nuevas estructuras de producción}

Ese proceso de inmersión en distintas fases clandestinas y la atomización de la industria zapatera ha supuesto la desaparición de las grandes empresas de producción integrada, en las que todo el proceso productivo, incluida la comercialización, se gestionaba bajo una sola dirección. Hoy, las firmas se refugian en estructuras mucho más flexibles, mediante las que asumen menos riesgos y, a la vez, gracias a las cuales resulta mucho más fácil la recuperación y reinserción de empresarios y trabajadores en el proceso productivo tras una quiebra o durante una crisis.

En este sentido, ha de hacerse hincapié en las características intrínsecas de la producción zapatera, una manufactura en la que, como tal nombre indica, el porcentaje del coste de la mano de obra resulta muy elevado respecto al valor final del producto. Se trata por naturaleza de una industria itinerante, en pos siempre de una mano de obra barata, dado que la cualificación de la misma es fácil y puede obtenerse de forma rápida, mientras que no presenta ninguna sujeción respecto a fuentes de energía, ni a la presencia de materias primas $^{7}$, ni siquiera a la cercanía con los mercados. En realidad, esta industria explota los denominados «yacimientos de mano de obra», factor que constituye uno de los componentes más destacados del valor final de la producción.

En la actualidad, las mayores imposiciones se deben al empleo de materias primas más sofisticadas, importadas en muchos casos (aunque su precio se eleva también por la especulación de intermediarios y almacenistas).

7 PONCE HERRERO, G., ob. cit., 1997, pp. 99-114. Si bien la presencia de materias primas —pieles fundamentalmente- en las proximidades del Valle del Vinalopó fue factor destacado en la génesis de la industria, hoy, como se ha visto, es aspecto muy secundario, y los canales de abastecimiento rebasan con frecuencia los límites internacionales. 
Sigue en importancia el coste de la mano de obra, con un incremento salarial que no ha podido ser absorbido por el proceso de tecnificación, debido a una legislación laboral poco flexible desde el punto de vista empresarial, que ha comenzado a demandar la consideración de «trabajo estacional» para las nuevas regulaciones laborales. En la actualidad se suceden de manera casi cotidiana coyunturas favorables y desfavorables, de forma tal que con ocasión de una gran demanda las empresas se ven con frecuencia imposibilitadas para atender todos los pedidos, los trabajadores desempeñan jornadas laborales intensas y extensas y se hace indispensable la búsqueda de apoyos no contractuales, recurriendo a la subcontratación o al subempleo de mano de obra sin vinculación legal. Esto es, se recurre a un vasto mercado secundario de trabajo.

Por el contrario, las épocas de escasez en la demanda son saldadas con verdaderas crisis de producción, y las ya de por sí reducidas plantillas de las firmas resultan todavía excedentarias, llegando, con frecuencia, a cierres temporales. Los acusados dientes de sierra en la demanda son causa de las dificultades existentes en el subsector para incorporar trabajadores de manera indefinida en las empresas. Los contratos temporales, renovados tras algún período de cese intermedio, son la práctica más habitual en la actualidad, cuando no impera el empleo informal ${ }^{8}$.

MERCADO LABORAL DE ELDA, 2002

\begin{tabular}{|lr|}
\hline tipos de contratos & \\
\hline eventual tiempo completo por circunstancias de la producción & 8.353 \\
eventual tiempo parcial por circunstancias de la producción & 1.574 \\
obra a tiempo completo & 1.452 \\
indefinido & 827 \\
bonificados e inserción & 712 \\
interinidad y jubilación parcial & 644 \\
obra a tiempo parcial & 489 \\
formación & 263 \\
prácticas y otros & 80 \\
fijo discontinuo & 63 \\
Total contratos & 14.457 \\
\hline
\end{tabular}

Fuente: INEM. Elaboración propia.

El empleo intensivo de la mano de obra lleva pareja una fuerte incidencia de las cuotas que los empresarios han de satisfacer en concepto de coberturas sociales, lo que repercute en el coste de la producción, y resulta especialmente gravosa en el caso de las regulaciones de empleo o de cierre definitivo de la firma. Tal circunstancia ha dejado descapitalizados con frecuencia a los empresarios afectados, y de ese modo se ha dificultado su reincorporación al proceso productivo. No obstante, esas coberturas sociales de desempleo han actuado como verdadero colchón amortiguador de la crisis que, de otra forma, hubiera adquirido tintes dramáticos, y paradójicamente ha posibilitado un incremento de la competitividad en los mercados internacionales, ya que los beneficiarios de esos subsidios por desempleo han seguido trabajando normalmente de manera informal, en las mismas empresas o en otras, que de esa manera han podido rebajar los niveles salariales. De hecho,

8 PONCE HERRERO, G., «La població activa», Geografia General dels Països Catalans, t. 3, Barcelona, Enciclopedia Catalana, 1996, pp. 270-292. 
estos resultan proporcionalmente más bajos que los obtenidos en los años de bonanza continuada. Ahora bien, ese descenso salarial aceptado por los parados que ya habían trabajado antes, ha repercutido negativamente en los salarios de los jóvenes que se incorporan por primera vez al trabajo, obligados a aceptarlos sin el complemento del subsidio de desempleo.

Todo ello ha tenido un claro reflejo en las estructuras jurídicas de las empresas. Hoy son muy pocas las que cuentan con una antigüedad significativa. Lo normal ha sido una sucesión de cierres y reaperturas de las mismas estructuras fabriles bajo nuevas formas jurídicas. La forma legal más empleada es la de la sociedad limitada, seguida de la sociedad anónima y de las cooperativas; frente a ellas son minoría las empresas individuales, por la búsqueda de aminorar riesgos y responsabilidades ante las eventuales quiebras.

\subsubsection{El recurso de la economía sumergida}

Además de los aspectos formales descritos, el nuevo modelo productivo se apoya en gran medida en la ocultación legal de una parte de la producción, estimada entre un $20 \%$ y un $40 \%$ según los municipios del Valle, con una variabilidad debida fundamentalmente al tipo de actividad concreta desarrollada en cada caso, de manera que los pequeños talleres auxiliares y complementarios escapan con mayor facilidad a la legalidad vigente. También se observa como el peso de la actividad informal es mayor en la elaboración de calzado que en la marroquinería. Además, en los núcleos tradicionales subsisten multitud de talleres que, con frecuencia, adoptan la fórmula de ocultar toda o parte de la actividad, mientras en los municipios rurales industrializados parece que tal circunstancia tiene menor peso porcentual. En este sentido, la economía informal es posible, entre otros aspectos ya descritos, por la existencia de importantes bolsas de desempleados cualificados, más nutridas siempre en las ciudades.

Ya ha sido comentada la configuración flexible de las plantillas y la incorporación temporal de refuerzos. Pero también es común la ocultación de una parte de la producción, para eludir el canon del I.V.A. o aminorar las bases impositivas en relación con las declaraciones de renta y de beneficios. Se emplea, de esa manera, una práctica de descapitalización de la empresa, de forma que una parte de los beneficios se convierten en dinero negro, imposible de reinvertir en la empresa y, normalmente, es desviado hacia los consumos privados (automóviles, residencias secundarias, etc.) y hacia diversas aventuras inmobiliarias, en buena medida atraídas por el desarrollo turístico del litoral vecino.

El modelo de plantilla flexible necesita para funcionar un volumen de población activa «de reserva», susceptible de ser aprovechada coyunturalmente. Para ello, es preciso que esa mano de obra no esté empleada, ni vinculada formalmente a ninguna empresa y, además, que los activos acepten las precarias condiciones laborales propuestas, que por lo común bordean la legalidad de los modelos contractuales, cuando no se soslayan directamente.

El trabajo no regulado tiene una larga tradición en el Valle del Vinalopó y forma parte consustancial de la cultura industrial forjada a lo largo de la historia — de empresarios y de trabajadores-. Antes de la crisis y del ajuste productivo, el trabajo informal constituía una opción atractiva para los trabajadores que, de esa manera, podían o bien compaginar la dedicación a las tareas domésticas con la producción industrial (en el caso de las mujeres), o bien conllevaba ventajas económicas tanto para empresarios como para trabajadores: los primeros podían gestionar una parte de la producción fuera de los cauces impositivos, y los obreros incrementar sus ingresos, mediante ritmos de destajo, «haciendo horas» en la misma fábrica o en otras y en sus domicilios, también sin dar cuenta legal. 
En los primeros años del ajuste, las compensaciones por despidos y cierres de las empresas, así como las subvenciones y ayudas (hasta de los ayuntamientos) para los desempleados — que no parados_- permitieron mantener esas prácticas y prolongar las ventajas para unos y otros. No obstante, en la actualidad, las bolsas de trabajadores que constituyen el recurso de las plantillas flexibles están formadas, fundamentalmente, por jóvenes y por otros colectivos que no perciben ayudas económicas para paliar su limitada incorporación al mercado laboral.

De esa manera, la economía sumergida repercute ahora directamente en un deterioro constante de las condiciones laborales y de los niveles salariales, en un proceso que ha sido denunciado por los sindicatos como una «vietnamización» de la mano de obra. Esto es, no es preciso deslocalizar la producción hacia países del tercer mundo, sino recrear en el distrito industrial bolsas de trabajadores con las mismas o parecidas condiciones, en aras de mantener la competitividad mediante la fórmula de aminorar los costes, con la ventaja añadida de su proximidad y nula conflictividad. La inyección reciente de nueva mano de obra inmigrada e ilegal, procedente del Magreb y de América del Sur, ha renovado las condiciones.

Si antes fueron las subvenciones directas de los gobiernos públicos las que mantuvieron el atractivo del recurso «mano de obra», ahora esas ayudas son más indirectas, y llegan a través del contexto general y de las favorables condiciones de vida creadas por las políticas sociales —el medio social-.

\section{Un sistema territorial de producción expansivo y en red}

El establecimiento de redes de empresas en estrecha interdependencia constituye rasgo destacado de los sistemas productivos locales. En el Valle del Vinalopó predominan las relaciones de carácter mercantil, vinculadas a la compra o a la venta de productos o servicios intermedios. De ese modo, buena parte de las relaciones son de tipo horizontal, entre empresas matrices, talleres especializados y empresas subcontratadotas de una parte de la producción. Se ha llegado a esta lógica territorial desde otra en que predominaban las relaciones jerárquicas, en las que algunas grandes empresas centradas territorialmente, y de producción integrada, subordinaban toda la producción de otras empresas auxiliares, por lo general dispersas por la periferia del sistema territorial de producción. De hecho, han llegado a coexistir ambas lógicas, si bien el establecimiento de redes horizontales de complementariedad entre PYMES parece fórmula emergente y más competitiva.

Desde el punto de vista espacial, en el Valle del Vinalopó se ha consolidado un sistema de producción industrial de escala subregional, con una estructura funcional especializada, aunque dispersa y en expansión. Puede decirse que, pese a que se ha producido una desintegración vertical de la producción, el Valle del Vinalopó funciona como un área industrial integrada verticalmente, ya que en él tienen lugar todas las fases de producción: se establecen relaciones verticales entre los diferentes establecimientos y talleres auxiliares y complementarios, a las que se suman las relaciones laterales establecidas con las industrias que producen los componentes utilizados y con las que prestan servicios especializados. Finalmente, todas ellas se benefician de una serie de infraestructuras y servicios de tipo general (financieros, administrativos, educativos y de capacitación, sanitarios, etc.) también implantados en el Valle, de forma que la densa maraña de flujos ha favorecido la integración espacial, si bien se mantiene la dualidad entre un centro, representado por las ciudades principales del Valle, donde se mantienen las unidades de decisión, diseño y gestión, así como los servicios generales, y una periferia subordinada, representada por 
municipios antes de economía rural, ahora en transformación, donde aumentan las unidades de producción industrial.

La difusión de la actividad industrial por el territorio ha supuesto la configuración de un nuevo modelo espacial de la producción y una nueva localización de las actividades, auspiciada por la descentralización de la producción y por su difusión territorial en busca del paradigma de la flexibilidad que generan las unidades de producción más pequeñas, pero también buscando la confluencia positiva de variables sociales e institucionales, que han ido cobrando peso, a veces decisivo en algunos municipios. La posibilidad de atomizar la producción ha sido fundamental en el proceso de difusión del sistema productivo por municipios pequeños, carentes de economías de aglomeración, que se compensan, sin embargo, por la proximidad entre ellos y con las principales ciudades donde radican los servicios generales y a la industria.

La organización territorial de la producción zapatera ha pasado desde un modelo monocentrado, caracterizado por la integración de la actividad y la polarización en unos pocos núcleos, a una fase intermedia en que fue configurándose un modelo multipolar, debido al fuerte crecimiento de la etapa fordista, en el que la producción siguió centrada/ integrada en las fábricas y las redes interempresariales siguieron siendo débiles, hasta llegar al actual modelo difuso, caracterizado por la segmentación de la producción y la localización específica de cada una de las fases conforme con las ventajas comparativas y competitivas del territorio.

Si bien la difusión arranca durante la fase de fuerte desarrollo y antes de la crisis, se ha señalado que tal proceso difiere del actual, ya que obedece a la insuficiencia de abastecer la fuerte demanda, imposible de satisfacer con la fuerza productiva de la fábrica integrada ${ }^{9}$, mientras el actual modelo se debe a la profunda reestructuración de la organización de las empresas y la conformación de un área o distrito industrial especializado, en el que se generalizan las relaciones entre empresas en aras de la cooperación y la complementariedad.

La nueva organización espacial obliga a redefinir el concepto de local, aplicable al sistema productivo desarrollado, hasta ahora asociado al sistema económico centrado en cada uno de los núcleos, para hablar con mayor propiedad de redes empresariales extendidas por un territorio amplio, que traspasa términos municipales y límites provinciales y choca, no obstante, en su expansión con las diferentes coyunturas socioeconómicas alcanzadas en cada municipio y con la iniciativas de los agentes sociales locales y, de manera especial, con las políticas sectoriales y generales desarrolladas desde las administraciones locales, de forma que el sistema productivo en torno al calzado alcanza una concreción diferente en cada municipio.

En la actualidad, mientras prosigue la descentralización por los municipios menores de antigua economía rural, aprovechando fundamentalmente los recursos de mano de obra y suelo, la industria explora nuevos procesos de deslocalización de escala mayor. Así, se han dado algunas experiencias con relativo éxito, tales como el salto a América central y del Sur, o las operaciones en los países del Este de Europa. En ese empeño se trabaja ya hace tiempo en el Norte de África (en especial con Marruecos y Túnez, con cuyas autoridades existen ya pactadas garantías). Se trata de explotar nuevos yacimientos de mano de obra barata, manteniendo las sedes de las empresas en los municipios del Valle, así como los servicios a la industria y las actividades más especializadas.

9 CIVIDANES HERNÁNDEZ, J. L., HERNÁNDEZ HERNÁNDEZ, G., «Dinámica industrial y áreas de especialización», Estructura económica de la Provincia de Alicante, Alicante, Excma. Dip. Prov., 1993, pp. 178179. 
Ya existe una importante colonia de empresarios alicantinos en Marruecos, que fabrican calzado completo o partes del zapato, aprovechando los bajos salarios medios: en octubre de 2000, el sueldo medio de un zapatero en ese país, con jornada de lunes a sábado, oscilaba entre las 25.000 y las 30.000 pesetas mensuales ${ }^{10}$. De hecho, una de las principales importaciones por el puerto de Alicante es la partida de partes de calzado, con un valor de 3.278 millones de pesetas, ocupaba el puesto número 12 en el orden de las importaciones en 1998. En ese sentido se han articulado estrategias para trasladar el calzado semihecho hasta las fábricas/almacén del Vinalopó, donde se les añade alguna fase final para poder ser comercializados como propios y en el mercado de la Unión Europea. Esto es, se reproducen las relaciones de subordinación jerárquica de diferentes unidades de producción muy separadas entre sí, aunque ahora, la empresa matriz no reviste las características de la gran empresa integrada.

La descentralización industrial, seguida del establecimiento de redes fluidas para la producción, se da tanto en la escala intraurbana, como sobre el territorio de la comarca, del sistema productivo industrial y llega, incluso, a alcanzar una envergadura intercontinental $^{11}$. Tal proceso sigue evidenciando el peso de la estrategia de competir abaratando costes $\mathrm{y}$, en concreto, explotando nuevos yacimientos de mano de obra barata. El propio Gobierno autonómico ha asumido como propia esa línea de actuación, como refleja el recién aprobado Plan de Implantación de Empresas en el Exterior, mediante el que prevé subvencionar a fondo perdido hasta el $50 \%$ de los estudios de viabilidad de los proyectos de radicación en el extranjero de empresas industriales valencianas ${ }^{12}$. Se llega así a la paradoja de que, mientras los gobiernos locales hacen todo lo posible por retener y ampliar el tejido empresarial, el gobierno autónomo apuesta más por los beneficios del capital y por la viabilidad económica de las empresas- que por su propio territorio ${ }^{13}$.

La fuga de empresas es coherente con las lógicas del capital $-\mathrm{y}$ la nueva división espacial del trabajo-; menos razonable parece el apoyo del Gobierno regional, conforme con la falta de alternativas de empleo y de incentivos a la innovación para mejorar la competitividad por diseño y calidad. Tal actitud, enfrentada con la de los gobiernos locales -al margen del signo político-, con la de sindicatos, e incluso con la de algunos dirigentes patronales ${ }^{14}$, puede empero insertarse en la estrategia más global, desarrollada por la patronal, de presionar a la baja en el coste de la mano de obra mediante amenazas de traslado.

\section{El protagonismo de los agentes locales}

En un contexto de pequeñas y muy pequeñas empresas, donde casi el $70 \%$ declara menos de 20 empleados, el esfuerzo innovador escapa, con frecuencia, a las posibilidades del núcleo empresarial. De ese modo, el esfuerzo innovador ha tenido que apoyarse en el empeño de algunos actores locales comprometidos con el desarrollo de sus municipios.

10 Diario INFORMACIÓN, 5-X-2000, «La industria auxiliar potencia sus negocios con fábricas marroquíes», p. 18. Elche.

11 VALENZUELA RUBIO, M., «La industria urbana, de la obsolescencia a la innovación», Industria y medio ambiente, Alicante, Dpto. Geografía Humana, Universidad de Alicante, AGE, 2000, pp. 15-34.

12 DOGV, 17/04/03/, «Orden de 11 de abril de 2003».

13 La directora del Instituto Valenciano de la Exportación (IVEX), el secretario de la patronal del calzado de Elche y el director comercial de la Federación de Industrias del Calzado Español (FICE), han promovido estudios de radicación de empresas de calzado alicantinas en Marruecos, Túnez y Rumanía «donde la mano de obra es más barata y así poder hacer frente a la fuerte competencia del calzado italiano», Información, mayo 2002.

14 Información, 09/05/03, «Las ayudas para el traslado de empresas dividen a la patronal de Elche y Elda». 
Entre ellos, fundamental ha sido la labor de las instituciones públicas de carácter municipal, que han podido moverse con suficiente holgura en el marco jurídico definido por las políticas sectoriales valencianas (industrial, desarrollo local y urbanismo de forma destacada). El desigual desarrollo socioeconómico alcanzado en las últimas décadas en cada municipio del Valle del Vinalopó, tiene que ver, fundamentalmente, con esas tareas de gobierno local comprometido o no, reactivas o proactivas. Menos eficaces han resultado las estructuras supralocales, foco de discordia entre municipios y entre partidos políticos, convertidas de hecho en plataformas artificiales para la captación de recursos económicos, y en almoneda para su reparto.

\subsection{La búsqueda de un proyecto para el territorio}

Una manifestación de la preocupación política por el entorno económico y social se concreta en la elaboración y puesta en marcha de planes estratégicos, como el Plan de desarrollo integral del Alto Vinalopó, y el Plan estratégico para el desarrollo del eje económico del Vinalopó, que afectaba a las comarcas del Alto y Medio Vinalopó. Ambos planes fueron el resultado de la iniciativa política de los ayuntamientos del Valle del Vinalopó, ante los efectos de la crisis económica padecida y las dificultades de la actividad industrial en el proceso de reconversión experimentado. Más reciente es el plan estratégico de Elche, Futurelx, que sigue apostando por la especialización productiva del calzado en torno a los paradigmas de diseño y calidad, junto con el desarrollo de servicios complementarios a esa actividad industrial. La existencia de tres planes estratégicos diferentes es muestra de la desunión del territorio, y del empeño de los agentes locales por desarrollar estrategias que favorezcan a su municipio y, como mucho, a los municipios vecinos más inmediatos siempre bajo criterios de subordinación funcional.

El Plan de Desarrollo Integral del Alto Vinalopó, de 1992-1993, cuenta con unas consideraciones de tipo social y otras marcadamente económicas, entendiendo que ambas van estrechamente vinculadas y que el desarrollo ha de atender de manera integral todas las facetas del complejo entramado socioeconómico y político de los municipios considerados, de forma que el desarrollo económico vaya seguido de mejoras sustanciales en la calidad de vida.

Respecto de la industria se destaca la importancia de la nueva estrategia de competitividad basada en la diferenciación del producto (su plasmación fue acompañada por campañas de calidad e imagen, tales como la de Calzado de Villena o Elda Prestigio). Las líneas de actuación propuestas se concretaban en la producción y en la comercialización y promoción. Respecto de las primeras, las estrategias insistían en la utilización de sistemas productivos basados en las tecnologías más avanzadas, para favorecer la competitividad y la calidad final del calzado. Se señalaba la importancia de la creación de una central de compras, tanto parar racionalizar la gestión del aprovisionamiento, como para impulsar un proceso de normalización y sujeción a estándares de calidad de las materias primas y los componentes utilizados. A su vez, mediante esa destacada logística se podría actuar en la rebaja de los costes y en la automatización de los procesos, una vez homogeneizados los componentes.

Esas mejoras debían ir acompañadas de estrategias de comercialización basadas en la calidad y en el diseño. Pero se insistía también en la necesidad de intervenir más activamente en los procesos de comercialización, mediante la creación y desarrollo de redes comerciales propias, en los mercados nacional y extranjero. Se señalaba como estrategia oportuna la creación de consorcios de exportación, creando estructuras asociativas que permitiesen a las pequeñas empresas estar presentes en los mercados con marcas propias, 
establecer estrategias de marketing conjunto y estudios de mercados de interés colectivo. Finalmente, se proponía la profundización en la mejora de la imagen, creando una etiqueta de calidad, en colaboración con el instituto tecnológico del calzado - INESCOP-.

Las propuestas del Plan Estratégico para el Eje de Desarrollo Económico del Vinalopó, de $1993^{15}$, consideraban fundamental la mejora de la red de comunicaciones intra y extra comarcales, para mejorar la transmisión de flujos e información entre los municipios del Valle del Vinalopó y, a la vez, para mejorar cualitativamente la posición relativa de la subregión en el arco de desarrollo del Mediterráneo. En ese sentido, se insistía en la necesidad de establecer en Elda un centro de actividades logísticas para el calzado, ubicado en el polígono industrial Campo Alto, que debería redefinir y mejorar sus comunicaciones viales, para acoger un centro de telecomunicaciones, un puerto de carga y conexión con el ferrocarril de velocidad alta.

Se señalaba la necesidad de fomentar la investigación y el diseño en todas las actividades industriales. En concreto, para el calzado y la marroquinería se proponía la creación de un instituto de investigación del cuero y calzado, en el seno de INESCOP, con la finalidad de profundizar en nuevos sistemas productivos, de organización y en nuevos productos, para mejorar la calidad y diversificar la oferta. De igual manera, se proponía ampliar las competencias de INESCOP para que pudiese actuar como incitadora de vivero de empresas, en actividades consideradas estratégicas para el calzado y con escaso interés entre la iniciativa privada, como la elaboración de productos intermedios, maquinaria y nuevas fórmulas químicas.

Para mejorar la productividad se proponía la acción asociativa de los empresarios, para crear un club de compras, la creación de un centro de reciclado de materiales, la utilización de energía más barata —el gas natural—, la revisión de los sistemas contractuales para ajustarlos a la marcada estacionalidad de la demanda. En esa línea se manifestaba la importancia de la formación de la mano de obra y del personal técnico, así como la necesaria reconversión de los cuerpos gestores de empresas y de los propios empresarios. Se planteaba el destacado interés estratégico del incentivo para la asociación y cooperación entre empresas.

El Plan consideraba que la planificación estratégica debería comprometer tanto a las administraciones (locales, provinciales, autonómicas y nacionales), como a las instituciones y diversos agentes privados, si bien se insistía en que el proceso debía ser liderado por las administraciones locales, aunque se invitaba a los agentes privados a liderar aquellas propuestas más entroncadas con su vocación.

\subsection{Un instrumento infrautilizado: la Mancomunidad intermunicipal del Valle del Vinalopó}

En 1982 se creo la Mancomunidad del Valle del Vinalopó ${ }^{16}$ que integra a los municipios de Elda, Petrer, Monovar y Sax, todos ellos comprendidos en el radio de 6 kilómetros $\mathrm{y}$, de hecho, funcionando como una pequeña red urbana subregional, con 101.869 habitantes en 2001, inmersa en un claro proceso de conurbación, ya consolidado entre Elda y Petrer, pero también muy próximo entre los demás municipios. La ciudad de Elda, sin magnitud suficiente para jerarquizar una auténtica área metropolitana, si actúa sin embargo como núcleo central, donde se han concentrado las funciones más especializadas.

15 RAMOS HIDAlgO, A., dir. Plan Estratégico del Eje de Desarrollo Económico del Vinalopó, 19931994. Proyecto no 60932009 .

16 El 30 de septiembre de 1982 se aprobaron los primeros Estatutos, modificados en 1984 y en 1990. 
Todo ese desarrollo territorial se ha dado sin que existan unas directrices de carácter supramunicipal para su ordenación, sino, más bien al contrario, mediante planeamientos y políticas sectoriales que han desconocido las realidades de los municipios vecinos, atendiendo sólo a cuestiones constreñidas dentro de los límites municipales. Se ha llegado así, con cierta frecuencia, a disposiciones contradictorias entre los intereses de ciudades vecinas.

El Artículo 20 de los Estatutos $^{17}$ establece que la Mancomunidad «podrá promover toda clase de actividades y prestar cuantos servicios públicos contribuyan a satisfacer las necesidades y aspiraciones de los vecinos de los municipios mancomunados», con un extenso ámbito competencial. Sin embargo, la debilidad del sentimiento de sumar esfuerzos se ha diluido ante el mayor vigor de la competencia creciente entre municipios para atraer o retener la actividad económica. A ello se suma, además, un componente de rivalidad política y de equilibrio en las decisiones que se concretan con inversiones sobre el territorio.

Así, con escasos recursos políticos y financieros, se ha constreñido su capacidad de gestión a materias que, pese a su elevado interés social ${ }^{18}$, infrautilizan el potencial de ese interesante organismo para el desarrollo de directrices de escala comarcal. Mientras, las políticas sectoriales siguen desarrollándose de manera individual, ahora mediante la gestión de los gabinetes de desarrollo económico locales.

\subsection{El Módulo de Desarrollo del Medio Vinalopó: otra oportunidad fallida de planifica- ción mancomunada}

El Módulo de Desarrollo del Medio Vinalopó, que tuvo sede en Elda, constituyó uno de los dos intentos de gestionar programas mancomunados desarrollados a comienzos de la década de los años 1990 en la Provincia. Financiados por el INEM, sus objetivos básicos fueron los de gestionar y desarrollar programas de fomento del empleo mediante la formación, creando escuelas taller y casas de oficio, pero también a través de la elaboración de estudios y análisis de coyunturas para la toma de decisiones en política local.

En diferentes municipios del Medio Vinalopó se celebraron cursos y talleres auspiciados por el Módulo entre 1993 y 1996. No obstante, por un lado la competencia creciente de las agencias locales de desarrollo y, por otro lado, la centralización de esos estudios en unidades provinciales y academias privadas concertadas, dejaron sin contenido el Módulo y provocaron su desaparición.

\subsection{El Centro de Desarrollo Rural del Alto Vinalopó (CEDER): los fondos estructurales europeos como vía de progreso}

El Centro de Desarrollo Rural del Alto Vinalopó surge como una posibilidad real de obtener fondos europeos para el desarrollo de regiones rurales y desfavorecidas. El CEDER tiene una composición marcadamente política, de manera que es el pleno, integrado por los diferentes alcaldes de cada localidad, el que decide el reparto de los fondos y los proyectos que deben ser financiados. De ese modo, un ayuntamiento de signo diferente al de la mayoría puede ver seriamente dificultados sus proyectos. Existe la queja de que el

17 MANCOMUNIDAD INTERMUNICIPAL DEL VALLE DEL VINALOPÓ, Estatutos modificados, junio de 1990.

18 Hoy se encarga de la gestión de los centros de drogodependencia y ocupacional, del albergue de animales y de una depuradora. 


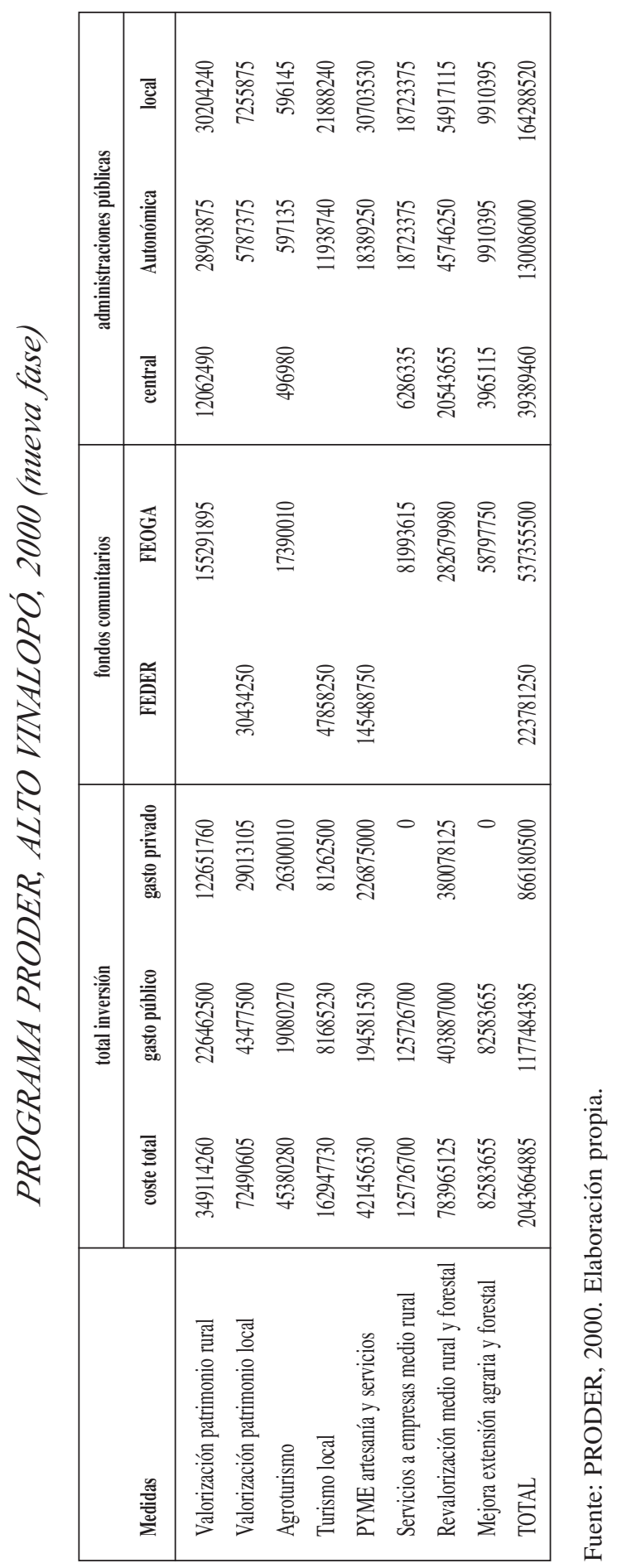


fondo se reparte proporcionalmente por municipios, conforme con su peso demográfico y, por ello, político, dejando en un segundo plano el verdadero interés de los proyectos.

También se han obtenido recursos a partir del Programa Operativo de Desarrollo y Diversificación Económica de Zonas Rurales, PRODER, con vigencia entre 1994 y 1999, por el que los municipios han podido presentar proyectos para obtener recursos de los fondos estructurales FEDER y FEOGA. Mediante la tramitación de esos proyectos, el CEDER del Alto Vinalopó tuvo acceso a unos fondos globales de 1.153'5 millones de pesetas, que se han distribuido como subvenciones diversas para los proyectos aprobados.

La oficina del programa PRODER en el Alto Vinalopó, inserta en el Objetivo 1 y por ello orientada hacia la búsqueda del ajuste estructural de las regiones menos desarrolladas, debe establecer medidas encaminadas a la puesta en valor del patrimonio rural y urbano de los municipios rurales. No obstante, el marcado desarrollo industrial de la comarca, y la discrecionalidad en la asignación de fondos, ha permitido que, a través de las medidas 5 y 6 del programa (consignadas para apoyo de pequeñas empresas, actividades de artesanía y servicios y para el desarrollo de servicios a empresas en el medio rural), en la práctica los fondos se hallan destinado al fomento de la actividad industrial, de la mano de los dos subsectores tradicionales en la zona: calzado y textil.

De igual manera, la inversión en la mejora de las condiciones del entorno ha favorecido la llegada de inversiones industriales foráneas, atraídas por las nuevas externalidades que han potenciado las ventajas comparativas de esos municipios en la periferia del sistema productivo industrial. La construcción de nuevos viales, la urbanización de asentamientos industriales preexistentes, la construcción de verdaderos polígonos industriales, las nuevas dotaciones de redes de abastecimiento, telefonía y energía eléctrica, han sido factores decisivos en el despegue o desarrollo industrial de los municipios menores. Debe ser destacado el caso de Salinas que, gracias a esos fondos y a un gobierno local comprometido con el desarrollo del municipio, ha pasado en una década de no contar con ningún establecimiento fabril y, por consiguiente, ningún puesto de trabajo industrial, a censar en el año 2000 un total de 29 empresas (16 de calzado y afines) que proporcionaban 456 puestos de trabajo ${ }^{19}$.

Tales fondos suponen una ingente movilización de recursos públicos y privados para las economías de estos municipios, que sin duda está repercutiendo beneficiosamente en su desarrollo económico y, de paso, en el mantenimiento de la viabilidad de las explotaciones agrarias, en la creación de infraestructuras y en la diversificación de la economía mediante el apoyo a las PYMEs, que constituyen la base de la industrialización emprendida.

19 PONCE HERRERO, G., «De reserva de mano de obra a sistema productivo local: el proceso de industrialización en Salinas», Salinas, sociedad y territorio, Universidad de Alicante, Ayto. Salinas, 2002, pp. 211-240. 
PROGRAMA PRODER, ALTO VINALOPÓ, 1996-1999

Inversión industrial (Ptas.) por ramos (número de empresas)

\begin{tabular}{|c|c|c|c|c|}
\hline empresas & $\begin{array}{c}\text { Modernización } \\
\text { del proceso }\end{array}$ & traslado & ampliación & creación \\
\hline calzado & 5 & 2 & & \\
\hline textil & 5 & 5 & 5 & \\
\hline materias plásticas & 3 & & 2 & \\
\hline madera & 2 & & & 1 \\
\hline extracción minerales & 2 & 1 & & \\
\hline energía & 1 & & 1 & \\
\hline servicios & 1 & & & \\
\hline transformación metales & 1 & & & \\
\hline cuero & & 1 & & \\
\hline materiales de precisión & & & 1 & \\
\hline artes gráficas & & & 1 & 3 \\
\hline reparaciones & & & & 1 \\
\hline servicios & & & & 1 \\
\hline creación de empleo fijo & 21 & 9 & 27 & 41 \\
\hline creación de empleo no fijo & 23 & 25 & 6 & 14 \\
\hline inversión & 368.262 .601 & 365.051 .336 & 585.984 .079 & 183.281 .495 \\
\hline subvención & 47.359 .396 & 43.395 .010 & 65.323 .085 & 32.957 .079 \\
\hline
\end{tabular}

Fuente: PRODER, Villena, 2000. Elaboración propia.

\subsection{El papel de las Agencias Locales de Desarrollo}

Parece claro que las estrategias de las empresas más dinámicas necesitan la colaboración de los agentes sociales para mejorar el entorno local en que se apoyan. Pero los entornos industriales tienen carencias de infraestructuras y equipamientos para uso industrial, y también carencias en los sistemas productivos, como las insuficiencias en la formación de la mano de obra y de los empresarios, la difusión de las innovaciones, las estrategias de cooperación o la formación de redes.

Buena parte de esas necesidades tienen una clara relación con los planes de urbanismo. Además, en las dos últimas décadas, el fuerte dinamismo económico, tecnológico y administrativo ha llevado a una necesaria transformación y renovación de los instrumentos tradicionales de planificación, otorgando una enorme capacidad de gestión a las administraciones locales, que tienen en ese campo un vasto espacio para desarrollar estrategias de política económica local ${ }^{20}$.

Esa tarea, entendida por los responsables políticos como un esfuerzo necesariamente colectivo, se ha visto complementada en algunos casos por la puesta en funcionamiento de gabinetes locales de desarrollo económico, con iniciativas propias y específicas para cada municipio, a veces en competencia directa con las del municipio vecino, pese a las recomendaciones de unas estrategias comunes para el conjunto que proponen los planes estratégicos elaborados.

Municipios como Elche (198.190 habitantes en 2001), Elda (51.816 habitantes), Villena (32.111 habitantes), Petrer (29.567 habitantes) y Salinas (1.264 habitantes), han acome-

20 VÁZQUeZ BARQUERO, A., Política económica local, Madrid, Ed. Pirámide, 1993. 
tido una destacada labor en ese sentido, aprovechando en mayor o menor medida las ventajas que los cambios operativos han puesto en manos de los planificadores y gestores locales.

En el proceso se ha evidenciado que las administraciones públicas locales se mostraban ineficaces en sus estructuras y funcionalidad, para asumir la gestión y dirección de las nuevas propuestas estratégicas ${ }^{21}$, tanto más las de los municipios pequeños. La nueva planificación pública intervencionista exigía una cierta filosofía empresarial para ganar eficacia y, a la vez, obtener la suficiente agilidad y flexibilidad para, por un lado, gestar y dirigir nuevas actividades y, por otro lado, para tramitar rápidamente las propias iniciativas y las de los agentes privados.

Con ese espíritu han surgido diversas empresas municipales, como PIMESA en Elche, IDELSA en Elda o INALVISA en Salinas. En otros casos, su dependencia jurídica del Ayuntamiento resta posibilidades de intervención ágil o constriñe la pluralidad de actuaciones posibles. Si bien, es preciso señalar la fuerte vinculación política existente en todos los casos, ya que de toda estrategia de desarrollo local se puede extraer un rédito político. Tal dependencia se acentúa cuando el técnico cuenta con un contrato temporal o está a expensas de que se consolide el servicio.

Esencial resulta para ser eficaces el tamaño y el número empleados, así como el propio equipo material de que dispone la oficina. En los casos analizados se observa una gran disparidad entre, por ejemplo, el tamaño que alcanza IDELSA, con sus diferentes departamentos y empresas municipales, y las agencias de desarrollo local de Monovar o Pinoso, con un solo técnico, en una pequeña dependencia municipal, que a menudo ha de desdoblar sus tareas para ocuparse de otros asuntos propios de la administración pública. Las posibilidades en las plantillas y en sus situaciones son tantas casi como municipios, lo que compromete su funcionalidad.

\subsection{El apoyo público a las PYMEs como fundamento del crecimiento económico}

Los procesos de ajuste (que no reconversión) de las empresas productivas en el Valle del Vinalopó han puesto de manifiesto, como en toda Europa, el valor de las pequeñas y medianas empresas para acomodarse a los nuevos modelos de organización difusa y producción flexible. Esas PYMEs constituyen el principal motor en la generación de puestos de trabajo y el cauce por el que las innovaciones se distribuyen entre las empresas del sistema productivo del Vinalopó.

Si bien ha sido en la iniciativa privada sobre la que ha recaído el mayor peso de la reestructuración industrial, no cabe duda de que las iniciativas públicas emprendidas, en materia de infraestructura generales y específicas, planeamiento urbanístico, empresas públicas de servicios, fomento del asociacionismo y otras, han contribuido decisivamente a la consolidación del nuevo modelo de producción, verdaderamente apoyado en el territorio.

Las iniciativas públicas locales han desarrollado un amplio campo de trabajo para identificar las necesidades de las empresas del municipio, sea cual sea su naturaleza, y para diseñar respuestas adecuadas a esas carencias. Así, además de mejorar el entorno, han abierto líneas de ayudas indirectas a la mejora de los sistemas de producción y organización, mediante información y tramitación de solicitudes, junto con mecanismos de financiación alternativos, como anticipos reembolsables, capital de riesgo, capital en empréstitos o sistemas de garantías recíprocas. El Ayuntamiento de Salinas, a través de INALVI-

21 VÁZQUEZ BARQUERO, A., 1993, ob. cit., p. 35. 
SA, ha dado pasos en ese sentido, facilitando un «capital semilla» a las empresas y ofertando la posibilidad de participar con capital riesgo.

En todo caso, resulta esencial para las agencias de desarrollo local definir paquetes de ayudas claras y específicas para las PYMEs, que incluyan medidas tales como un acceso más fácil a los servicios financieros, a las subvenciones y a las necesidades formativas de la empresa en las diferentes etapas de su ciclo vital: inicio de las actividades, ampliación o cierre (en este caso paliaría los efectos dramáticos de buena parte de los cierres en el calzado, seguidos de desempleo, fraudes e impagados).

Desde esas agencias, se hacen significativos esfuerzos para elaborar diagnósticos coyunturales en cada municipio. Hasta ahora, trazado el diagnóstico, los agentes locales esperaban la demanda de servicios por parte de los empresarios. La experiencia y el conocimiento del medio empresarial (donde es acusada la falta de tiempo del pequeño empresario: «gerente», «contable», «comercial» y «trabajador» de su firma), ha dado pie a nuevas iniciativas más activas, mediante las que se asiste al empresario en su propia empresa.

En Petrer, la agencia de desarrollo económico ha establecido el programa de Asesoramiento Empresarial Puerta a Puerta, mediante el que dos técnicos se desplazan a cada uno de los establecimientos industriales para dar al empresario toda la información de interés recabada por la concejalía: en la campaña de 2001 se llegó a 110 empresarios, y en la de 2002 a 112 empresarios.

De ese trabajo «puerta a puerta» se concluyó que gran parte de los asistidos desconocían la existencia de la agencia de desarrollo local. En los cuadros adjuntos se ha establecido el orden de preferencia de los diferentes temas que, como se observa, cambiaron en uno y otro año, conforme con las coyunturas. Esto es, en 2001 interesó sobre todo las «ayudas» y la incorporación de la Ley de Prevención de Riesgos Laborales, seguidos de tres temas vinculados con el comercio exterior. Conforme con el carácter señalado de estas PYMEs, las nuevas tecnologías fue tema menos demandado, al igual que otros aspectos como el medio ambiente, el mercado laboral, la calidad y la formación continua. Sin embargo, en 2002, la información sobre medio ambiente fue la más valorada, seguida de la formación de nuevos trabajadores y de las ayudas. Los temas urbanísticos alcanzaron relevancia por cuanto la puesta en marcha de un nuevo Plan General y la creación de un nuevo polígono industrial de promoción pública reactivaron el debate sobre el entorno en que se asienta la producción.

PETRER, ASESORAMIENTO EMPRESARIAL PUERTA A PUERTA

\begin{tabular}{|lr|lr|}
\hline ramos & año 2001 & ramos & año 2002 \\
\hline calzado & 37 & calzado & 50 \\
marroquinería & 3 & marroquinería & 22 \\
auxiliar calzado & 25 & auxiliar calzado & 6 \\
talleres mecánicos & 2 & plantillas & 4 \\
mayoristas & 16 & patrones & 5 \\
hornos de pan & 8 & tacones & 4 \\
carpinterías & 2 & curtidos & 3 \\
cristalerías & 2 & carpintería metal & 3 \\
asesorías & 7 & alimentación & 1 \\
otros & 8 & otras & 14 \\
total & 110 & total & 112 \\
\hline
\end{tabular}

Fuente: Ayto. Petrer. Elaboración propia. 
PETRER, ASESORAMIENTO EMPRESARIAL PUERTA A PUERTA, ORDEN DE INTERÉS DE LOS DIFERENTES TEMAS DE INFORMACIÓN

\begin{tabular}{|lr|lr|}
\hline año 2001 & $\mathbf{n}$ o orden & año 2002 & \% interés \\
\hline ayudas & 11 & medio ambiente & 11 \\
prevención riesgos laborales & 10 & formación nuevos trabajadores & 8,9 \\
PYMEs comerciales & 9 & ayudas & 7,1 \\
comercio exterior & 8 & urbanismo & 5,4 \\
extranjero & 7 & fomento unión & 4,5 \\
nuevas tecnologías & 6 & calidad & 3,6 \\
contratación & 5 & extranjeros & 2,7 \\
medio ambiente & 4 & patentes y marcas & 1,8 \\
calidad & 3 & euro & 1,8 \\
formación continua & 2 & riesgos laborales & 0,9 \\
euro & 1 & & \\
\hline
\end{tabular}

Fuente: Ayto. Petrer. Elaboración propia.

Puede concluirse que, tal como señalaba la agencia de desarrollo local, la mayor parte de la empresas propias del calzado en el Valle, por su tamaño y dinámica, no cuentan con estructuras apropiadas ya no sólo para innovar por sí solas, sino incluso para acceder a la información. Del trabajo destaca también la influencia de las coyunturas —el día a díaen el horizonte de las preocupaciones empresariales, que explica las variaciones en los temas que han despertado mayor interés. Por último, cabe consignar el bajo interés mostrado por aspectos más vinculados con la innovación como las nuevas tecnologías, la formación continua, la calidad o las marcas y patentes. Con todo, las modificaciones habidas en el servicio prestado pueden ser responsables también de esas variaciones.

También es competencia de la iniciativa pública la mejora de las sinérgias entre las PYMEs, los centros de transferencia de tecnología - INESCOP_, otros centros de investigación y con las universidades — Departamentos e Institutos de Investigación, Oficina de Transferencia de Resultados de la Investigación (OTRI), Fundación Empresa Universidad (FUNDEUM), Gabinete de Iniciativas de Empleo (GIPE)—, empresas y organismos que a menudo funcionan de forma descoordinada o, simplemente, no son utilizados por las empresas por desconocer los cauces de acceso y las posibilidades que brindan. Muchos ayuntamientos del Valle tienen firmados convenios de colaboración y apoyo científico y tecnológico con las universidades de Alicante que no alcanzan todo su potencial.

En ese sentido, una necesidad básica consiste en definir una red de conexión eficaz entre empresas y centros de investigación y, además, con empresas que garanticen la transferencia de tecnología. También con las empresas que prestan servicios más elementales pero cualificados: diseño, marketing y otros. No cabe duda que para el desarrollo local y regional resulta fundamental estrategias que potencien la innovación y el desarrollo tecnológico, I+D+T.

En Elda han surgido algunas iniciativas en esa línea, unas auspiciadas por el INESCOP, como los programas informáticos para la fabricación de hormas o de fabricación rápida de componentes de calzado, y otras directamente en el seno de las empresas, como el programa Horma 2000, desarrollado por una empresa de esa ciudad, que ya se exporta a otros países productores ${ }^{22}$.

22 Aunque desde INESCOP se están desarrollando esos y otros programas, el sistema Horma 2000 ha sido desarrollado por el grupo industrial Aguado, en la primavera de 2000, y es exportado a Italia. 


\section{Redes sociales de cooperación para el fomento de la innovación territorial}

El individualismo de los empresarios del calzado se ha forjado en una cultura de competencia directa entre ellos mismos, que se extiende desde el aprovechamiento de los recursos del entorno, tales como la mano de obra - la cualificada y la barata-, los talleres auxiliares o los diseñadores, hasta la competencia en los mercados, en diseño, en calidad y en precios. La fuerte dependencia padecida por los fabricantes respecto de las grandes comerciales estadounidenses fue configurando en el sistema productivo industrial una especie de caldo de cultivo que favorecía la competencia entre las empresas que aspiraban a un pedido de los americanos. Se desarrollaron así diversas estrategias encaminadas a conseguir los encargos en dura competencia con los empresarios vecino, aún a costa de rebajar precios.

Ha tenido lugar, de ese modo, una especie de lucha ecológica por la supervivencia, entre las empresas, que persiste hoy por cuanto el papel de las nuevas comerciales —ahora en manos de los antiguos empresarios que padecieron los métodos de las comerciales americanas - sigue siendo el mismo, y por ello sigue fomentando la rivalidad entre empresas locales, circunstancia reñida con la necesaria colaboración que se auspicia desde todas las instancias.

Desde los sindicatos se hace hincapié en la necesidad de incentivar una verdadera cultura empresarial, en un colectivo de empresarios formado de manera espontánea, hechos a si mismos desde los puestos de trabajo en otras empresas, forjados en la lucha corta y en la competencia con sus vecinos, que conocen el medio en que se desenvuelven - el contexto productivo- y saben obtener el máximo beneficio de él, pero se desentienden de los mecanismos de presencia y competencia en los mercados, que dejan en manos de otros, un tejido empresarial inspirado en el acceso rápido a grandes beneficios, que mantienen unas prácticas de sucesivas aperturas y cierres que evidencian un notable desapego con la empresa y con la marca.

Desde la patronal se defiende que la competencia empresarial es sana y estimula el tejido productivo. Ese principio influye decisivamente en la manera en que se considera el asociacionismo, que se busca de forma puntual, para actuaciones muy concretas, pero al que no se prestas excesivo interés. La asociación para la adquisición de materias primas se plantea como asunto difícil por la enorme diversidad de producciones y, por tanto, de materiales y componentes que sería preciso almacenar para dar cumplida satisfacción a los asociados. Además, por los cambios constantes de la moda se correrían riesgos de grandes inmovilizados que se prefiere desviar hacia las comerciales de esos artículos, pese a tener que pagar más por ellos. Las series cortas han acabado con las posibilidades de realizar grandes compras de cada uno de los componentes del calzado, como si se hacía en épocas anteriores.

La asociación para la producción tampoco resulta interesante desde el punto de vista empresarial, ya que la nueva fábrica flexible y descentralizada permite ajustar los ritmos de producción a cada coyuntura, bajo las fórmulas de la subcontratación. No obstante, se avanza en este campo gracias a las asociaciones de empresarios para compartir diseñadores - modelistas - de prestigio.

Finalmente, la agrupación de empresarios para la comercialización parece ser el ámbito donde se percibe de manera más clara la necesidad de asociarse. Esa falta de recursos para presentarse de manera individual en las ferias y de mantener la presencia en los mercados internacionales provoca entre los empresarios del distrito la necesidad de asociarse, especialmente entre las empresas de menor tamaño. No obstante, a veces esa cooperación no va más allá de ser un trámite burocrático para poder acceder a determinadas subvenciones y 
ayudas para asistir a ferias o para exportar, ya que cada empresa monta luego su propio stand y realiza sus negocios de manera individual.

Desde la Cámara de Comercio se potencia el asociacionismo, si bien se indica también el perfil y la finalidad de esas asociaciones: La competencia exige que los industriales tengan asociaciones fuertes que, al mismo tiempo que les protegen e informan, puedan ser germen de acciones conjuntas de promoción exterior ... el asociacionismo debe tender a aprovechar la unión de las industrias, tanto a la hora de crear consorcios de importación o exportación, como para investigar diseños, intercambiar tecnologías y acceder a las ayudas públicas ${ }^{23}$. De hecho, la primera parte del párrafo es la que define la situación actual del asociacionismo en el sistema productivo industrial del calzado alicantino: proteger e informar. Las asociaciones de industriales tienen como finalidad principal la de defender a sus asociados frente a las decisiones de las administraciones públicas, por un lado, y frente a las reivindicaciones de los trabajadores por otro lado. Complementan sus objetivos con la difusión entre sus asociados de informaciones diversas, sobre ayudas, empresas complementarias, ferias y campañas de ventas entre otras.

Se trata, en general, de redes de cooperación articuladas a partir de la iniciativa pública, que está logrando salvar las reticencias de los diferentes actores locales. De ese modo, revisten por lo común el aspecto de medidas reactivas, en general para dar solución a problemas existentes, tales como la carestía de las materias primas - central de compras-, la negociación con los sindicatos, o la búsqueda de soluciones a las deficiencias en la comercialización.

En la segunda parte de la cita se expresa el deseo de que el asociacionismo supere esa etapa inicial en que todavía hoy se mantiene, para convertirse en nuevo insumo de desarro1lo. Se insiste en potenciar los aspectos comerciales -importación y exportación- y acceso a ayudas públicas, pero también se manifiesta la necesidad de llegar a estadios de complementariedad para incorporar estrategias de innovación y desarrollo, a partir de la creatividad, el diseño y el intercambio de experiencias y tecnologías para la producción.

Sin duda, el subsector avanza en esa dirección, como muestran experiencias recientes de agrupaciones para el diseño, para la presencia en ferias, para la búsqueda de ayudas y para la exportación. Más lentamente se avanza en la necesaria transmisión horizontal de nuevas tecnologías por intercambio de experiencias. En esa línea, siempre es necesaria la mediación del INESCOP, o de otro centro de transferencia de investigación, sobre el que recae el mayor esfuerzo en investigación, que desarrolla sus prototipos en combinación con una o varias empresas elegidas por su predisposición a cooperar, así como por su capacidad tecnológica.

Ejemplo de la percepción que los empresarios zapateros mantienen todavía hoy del asociacionismo es que la Asociación de Industriales del calzado del Valle de Elda (AICVE) cuenta con 100 asociados, cuando en 1999 el censo de industriales del ramo ascendía a 1.018 en el Medio Vinalopó ${ }^{24}$.

Con todo, frente a esas actitudes de cooperación coyuntural, se abren nuevas líneas estratégicas de cooperación, que pretende ser proactiva y de carácter permanente. En ese sentido, la mayor parte de las estrategias se enmarcan en experiencias conjuntas para el descubrimiento de nuevas oportunidades de mercado - misiones comerciales- . Otros proyectos se han centrado en la oferta de líneas de productos que se complementan entre sí

23 Presidente de la Cámara de Comercio, Industria y Navegación de Alicante, discurso en la Noche de la Economía Alicantina, diario El País, 17-XI-2000.

24 CÁMARA DE COMERCIO, INDUSTRIA Y NAVEGACIÓN DE ALICANTE, Censo de Actividades Económicas, según I.A.E., 1999. 
— calzado de descanso, calzado deportivo, calzado de vestir, bolsos, guantes, cinturones y otros complementos, elaborados por diferentes empresas bajo un mismo criterio de diseño, calidad, materiales, colores y texturas-. Existen agrupaciones de ese tipo, como el Grupo Petrer, Cavex o Alius en el Medio Vinalopó. En esencia, se trata de penetrar con un paquete integrado en los segmentos de mercado de mayor calidad, mancomunando en el esfuerzo a diferentes pequeños empresarios bajo un proyecto común, definido y diferenciado.

Puede concluirse que, si bien se dan figuras bastante completas del diamante de la cooperación, se trata en la mayor parte de los casos de formas de cooperación de carácter reactivo y coyuntural.

\section{Conclusiones: la innovación social en cabeza del proceso}

Característica destacada de los territorios innovadores es la estrecha simbiosis establecida entre innovación empresarial e innovación social. Este último concepto adquiere gran complejidad y se muestra difícil de aprehender y cuantificar (MÉNDEZ, 2002). Una adecuada aproximación puede obtenerse desde el estudio de la posible existencia de clima social de progreso, que incentive el desarrollo integral del territorio. La larga tradición en la fabricación de calzado en el Valle del Vinalopó permite hablar de una «cultura zapatera», que va más allá de la acumulación sedimentaria de conocimientos profesionales. Sentida como concepto existencial, se expresa como modo de vida, tanto en obreros como en empresarios ${ }^{25}$.

Sin llegar a constituir elemento determinante de los comportamientos, en la cultura zapatera del Vinalopó pueden identificarse varios de los elementos que propician la innovación social, sintetizados como la cultura y la triada del desarrollo local ${ }^{26}$. Así, en el Valle se da el conocimiento codificado, fácilmente aplicable y de naturaleza ubicua, vinculado a la tecnología madura de la fabricación de calzado — know how - . De igual modo, pueden ser detectados conocimientos enraizados localmente, que adquieren sentido sólo en clave local - como ocurre con muchas de las relaciones contractuales y en el mercado de trabajo- - La densa red de relaciones sociales, culturales e institucionales entabladas entre los habitantes y las instituciones de esta red de pequeñas ciudades, contribuye al mutuo conocimiento y al establecimiento de relaciones empresariales basadas en la confianza y la corresponsabilidad: la reputación ha sido hasta fechas bien recientes, uno de los activos más valorados por los zapateros —obreros y empresarios_-, si bien hoy es valor afectado.

Ahora bien, todo ello no tiene una repercusión directa y tangible en la innovación empresarial. La función social del empresario, que ha sido muy destacada en épocas pasadas (la fábrica ha sido escuela profesional, cívica y política ${ }^{27}$ ha quedado devaluada

25 PONCE HERRERO, G., MARTÍNEZ PUCHE, A., La industria del calzado en el Alto Vinalopó (18501977), Alicante, Universidad de Alicante, Asociación comarcal de industriales de calzado del Alto Vinalopó, 2003, 398 pp. En las entrevistas realizadas a empresarios y trabajadores se evidencia la forja de una mentalidad de zapatero, con el doble rasero de obrero y de empresario, manifiesta ya en los años 1920, que perfila el compromiso social y el carácter emprendedor tanto de unos como de otros. El salto frecuente de obrero a pequeño empresario y viceversa (con ocasión de las crisis cíclicas), así como la escasa longevidad de las empresas (que en pocas ocasiones sobreviven a su fundador) refuerzan el sentimiento de pertenencia a una sola clase social, definida por «ser zapatero». Se entiende así que, desde antiguo, hayan sido los sindicatos los primeros en reivindicar mejorar técnicas y estructurales en la industria.

26 ALBERTOS, J. M., «Cultura, innovación y desarrollo local», Proyecto coordinado Cambios organizativos y tecnológicos en los Sistemas Productivos Locales de España. Análisis regional comparativo de los procesos de innovación en el territorio, 2003, en prensa.

27 PONCE HERRERO, G., MARTÍNEZ PUCHE, A., ob. cit., 2003, 398 pp. 
precisamente por su falta de propensión a invertir en la modernización de la empresa. Las relaciones contractuales han ido ensanchando el mercado secundario de trabajo. Pese a que se ha extendido la idea de la supervivencia en el mercado gracias a la calidad, existe una cierta aversión al cambio y a la introducción de nuevos hábitos tecnológicos: se calcula el riesgo y se avanza lo suficiente para seguir siendo competitivos una campaña más; esto es, se trazan estrategias competitivas de muy corto alcance (en la mayor parte de los casos de naturaleza reactiva).

Puede decirse, por ello, que la innovación social va por delante de la innovación empresarial. Son las instituciones las que desarrollan las líneas de actuación más innovadoras. En general, allí donde se cuenta con gobiernos locales comprometidos, las estrategias sectoriales han sido integradas en directrices globales encaminadas a la ordenación del territorio, apoyados en planes estratégicos y guiadas por agencias de desarrollo local bien gestionadas. En todos los casos, fundamental ha sido la superación del concepto clásico - racionalista- del urbanismo y de los Planes Generales, cuya primera versión tuvo un grave impacto en el tejido empresarial y en la deslocalización de firmas ${ }^{28}$. Las nuevas formulaciones, más flexibles, se han convertido en verdaderas herramientas para potenciar el desarrollo industrial — cuantitativa y cualitativamente-, sobre todo a partir de la puesta en el mercado del suelo de grandes ofertas de suelo industrial equipado a precios bajos y muy bajos (incluso en alquiler o cesión), promovidos y subvencionados por los propios ayuntamientos.

De igual manera, han sido los gobiernos locales los que han puesto en marcha estrategias encaminadas a la mejora de la calidad de vida, en sentido general, con claras repercusiones tanto en el medio ambiente como en el bienestar social. Bajo la marca de Agenda 21 se han abierto nuevas líneas de actuación en Elche, Elda, Petrer, Villena y otros municipios del Valle, planteadas siempre desde una auditoria medioambiental del municipio, para adecuar los hábitos y mejorar las prácticas de empresas y ciudadanos, incorporando nuevos equipos y servicios más apropiados — recogida selectiva de residuos y su tratamiento: depuradoras, plantas de reciclaje-. También son los ayuntamientos los que desarrollan más activamente esfuerzos por la inserción laboral de los desempleados y de los colectivos más desfavorecidos. Aunque, en este sentido, ni la oferta pública - agencias desarrollo local y SERVEF_ - ni la privada — academias concertadas — centran sus enseñanzas en las distintas fases de elaboración del calzado ${ }^{29}$, a lo sumo en algunos aspectos tangenciales, como idiomas, diseño gráfico y técnicas de gestión empresarial o de ventas. Tal situación obedece al doble criterio de, por un lado, diversificar la dedicación laboral de estas ciudades y, por otro lado, seguir considerando que el oficio de zapatero se adquiere sólo como aprendiz en las fábricas.

28 PONCE HERRERO, G., «El planeamiento urbano: de traba a instrumento de desarrollo local en los municipios industriales valencianos», La ciudad, nuevos retos nuevas respuestas, VI Coloquio de Geografía Urbana, León, 2003, pp. 275-286.

29 Por el contrario, la mayoría de cursos se orientan hacia la capacitación en oficios como albañilería, fontaneros, electricistas, ebanistas o instaladores de gas, e incluso hacia la recuperación de viejos oficios artesanales, tales como canteros, herreros y hasta encaje de bolillos que, si bien cumplen un papel en la recuperación del patrimonio, son tareas poco demandadas por el sistema productivo industrial del Valle del Vinalopó. 
